\title{
Penetrating Trauma in Children
}

\author{
By Bryan A. Cotton and Michael L. Nance \\ Philadelphia, Pennsylvania
}

\begin{abstract}
Penetrating injuries account for $\mathbf{1 0} \%$ to $\mathbf{2 0} \%$ of all pediatric trauma admissions at most centers. Gunshot wounds are responsible for the overwhelming majority of penetrating traumatic injuries and have a significantly higher mortality rate than do blunt injury mechanisms. The management of penetrating injuries can be quite challenging and often requires rapid assessment and intervention. Specific management principles are guided by the anatomic location of injury, the determination of trajectory, and the suspected organs injured. Management approaches have been adopted in large part from the more robust adult experience. However, application of these strategies to similar lifethreatening injuries in the pediatric population appears appropriate.
\end{abstract}

(c) 2004 Elsevier Inc. All rights reserved.

D ESPITE INTENSIFIED EDUCATIONAL campaigns and increased efforts toward the prevention of childhood and adolescent injuries, trauma remains the leading cause of death and disability. ${ }^{1}$ Penetrating injuries are responsible for more than $10 \%$ of admissions at most major pediatric trauma centers, with firearm injuries accounting for almost $7 \%$ of patients. According to the 2003 annual report of the National Trauma Data Bank (NTDB), penetrating mechanisms accounted for approximately $20 \%$ of all injuries (and 20\% of deaths) in those less than 19 years of age. ${ }^{2}$ Penetrating injuries accounted for more than $13 \%$ of both intensive care unit and total hospital days. More concerning, the lethality of penetrating injuries (gunshot and stab wounds) was threefold greater than that of blunt injury mechanisms (motor vehicle related, pedestrian injury, falls). ${ }^{2}$ Thus, a thorough understanding of the management principles for penetrating injuries is necessary for those involved in the care of the pediatric trauma patient.

\section{WOUNDING MECHANISMS}

Despite recent decreases in firearm injuries nationally, gunshot wounds (GSW) remain the most common cause of penetrating trauma in children and adolescents ${ }^{3}$ (Fig 1). The incidence of firearm injuries rises dramatically beginning at age 12 and peaks earlier than other mechanisms (eg, motor vehicle collisions) at age 19. GSW injuries are associated with a mortality rate of almost $17 \%$, higher than any other mechanism of injury. ${ }^{2}$ The mortality risk is higher in younger children compared to adolescents, which may be related to the closer proximity of vital structures and the smaller frame in the younger ages. ${ }^{4,5}$ Firearm injuries are responsible for almost 10 deaths each day in the United States pediatric and adolescent population. ${ }^{6}$ Recent trends have also noted an increase in both the average number of wounds per patient as well as the average Injury Severity Score (ISS) for the pediatric GSW population.?

Shotgun wounds account for almost $20 \%$ of firearmrelated injuries in children and adolescents. The lethality of these weapons, which is related to their massive projectile dispersion and higher kinetic energy, is much greater than that of more commonly used firearms and may be of even greater concern in the smaller child than the adult. ${ }^{5}$ Management of these injuries can prove quite challenging, as often many body cavities are injured simultaneously.

An estimated 30,000 air-rifle injuries occur each year in the United States. Although frequently underappreciated as a weapon, these rifles can produce muzzle velocities greater than many low-velocity handguns and rifles. ${ }^{8}$ While the injuries sustained by most children with an air-rifle injury are minor, serious or even fatal injuries can occur, mandating thorough evaluation of all such injuries.

Despite the media attention of children and adolescents carrying firearms in schools, several studies have noted that most students (especially elementary and middle school children) are more likely to conceal a knife or similar bladed weapon..$^{9,10}$ Du Rant and colleagues found that middle school students were almost five times more likely to carry a knife or similar weapon than a firearm (14\% vs. $3 \%$ ) to school. ${ }^{10}$ Although the incidence of fatal stabbings in children has remained stable over the past two decades, nonfatal stabbings have increased and continue to rise. ${ }^{11}$

In children, impalement injuries are uncommon but are frequently fatal secondary to life-threatening injuries to abdominal organs and major retroperitoneal vascular structures. Most cases of impalement in childhood occur at home and are a result of falls or falling objects. ${ }^{12,13}$ These objects should be carefully removed under direct vision, with great care taken to debride tissue along the course of injury. There is often extensive tissue destruction and contamination of the wound with debris such as dirt, wood, and even the patient's clothing. ${ }^{14}$ Considering

From the Department of Surgery, Hospital of the University of Pennsylvania, Philadelphia, PA and the Department of Surgery, Children's Hospital of Philadelphia, Philadelphia, PA.

Address reprint requests to Michael L. Nance, MD, Department of Surgery, Children's Hospital of Philadelphia, 34th and Civic Center Boulevard, Philadelphia, PA 19104.

(C) 2004 Elsevier Inc. All rights reserved.

1055-8586/04/1302-0004\$30.00/0

doi:10.1053/j.sempedsurg.2004.01.004 


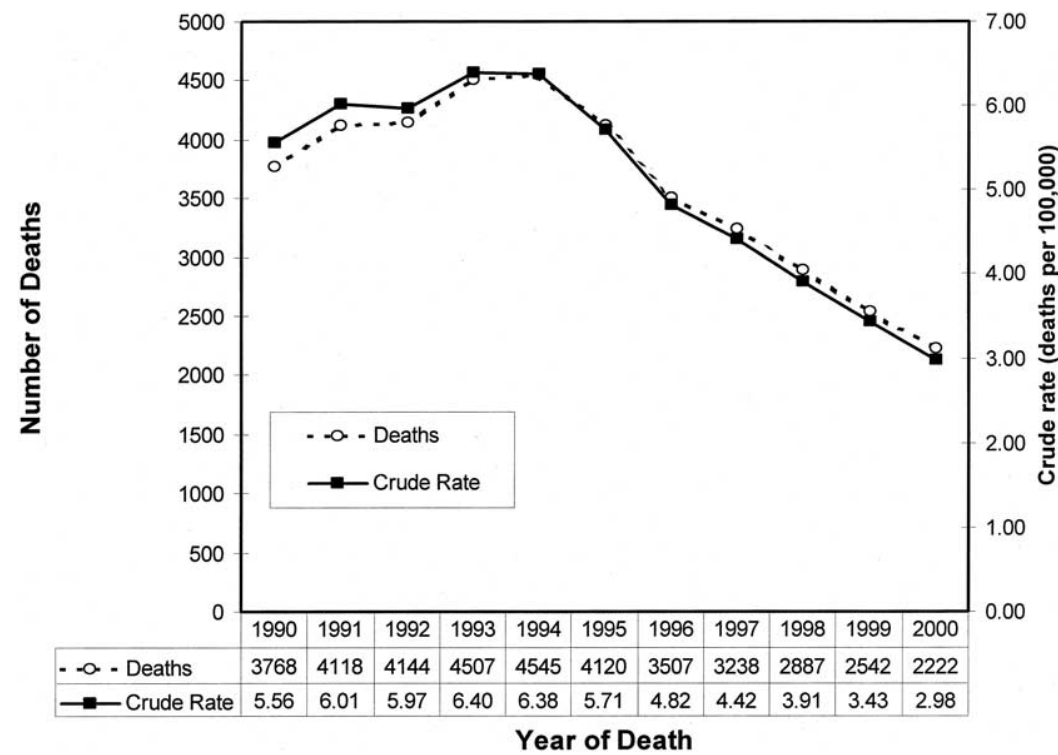

Fig 1. Trend in firearm-related mortality (absolute number and rate per 100,000) in the pediatric and adolescent population in the United States. (Adapted from CDC WISOARS data set. Accessed October 22, 2003. Available at: http:// webapp.cdc.gov/sasweb/ncipc/mortrate.html) this, broad-spectrum antibiotics and tetanus prophylaxis are indicated. The impaling object should be left in place until arrival in the operating room, but may require trimming or cutting to expedite extraction. Premature extraction can result in catastrophic hemorrhage. ${ }^{12-14}$

\section{RESUSCITATION ISSUES SPECIFIC TO PENETRATING TRAUMA}

\section{Primary Survey}

As with victims of blunt trauma, children presenting with penetrating injuries should be initially evaluated using the Advanced Trauma Life Support (ATLS) guidelines. ${ }^{15}$ The primary survey includes a rapid evaluation of the airway and breathing. Penetrating injuries to the neck can often compromise a patient's airway and surgical intervention may be required for definitive control. The majority of patients, however, can be maintained with bag-valve mask ventilation until semi-elective, controlled intubation is possible. With regards to breathing and ventilation, penetrating wounds to the neck and torso can produce a tension pneumothorax. If clinically suspected, this should be initially addressed with needle decompression. Formal decompression with an appropriate-sized chest tube may be necessary following procedure.

An elevated heart rate is classically the earliest indicator of hemorrhagic shock in the pediatric patient. Children frequently maintain their blood pressure until late in the course of hemorrhagic shock and once hypotensive may deteriorate precipitously. Large-bore intravenous access should be established for volume resuscitation and possible transfusion requirements. Placement of femoral lines should be avoided in patients with pene- trating torso injuries. Penetrating injuries require a baseline blood count and type and crossmatch at a minimum.

The primary survey is concluded with a quick neurological assessment and complete exposure of the patient. Full exposure in these patients is mandatory and should be done at the time of the primary survey.

Impaled objects noted at this time should be left (and possibly secured) in place. After all ventral wounds have been noted and all potential GSW marked with radioopaque clips, the patient should be log rolled to fully evaluate the back, axillae, and perineum.

\section{Prehospital and Preoperative Fluid Resuscitation}

Several authors have proposed limiting, even withholding, fluid resuscitation in this patient population until operative control of active bleeding is achieved. ${ }^{16-18}$ By limiting the volume of resuscitation in both the prehospital and preoperative setting, ongoing hemorrhage would theoretically be attenuated by preserving any intact clot, minimizing dilutional coagulopathy, and keeping the blood pressure low. The survival rate in the delayed fluid resuscitation group was significantly greater in the immediate resuscitation group in this study. There are some issues regarding the patient selection for the compared cohorts in this article and similar data is not available in the pediatric population subsequently this approach cannot be advocated at this time.

\section{Blood and Operating Room Availability}

As with all trauma patients, the treating facility should ensure the immediate availability of uncrossed matched blood. Although an initial fluid challenge with Lactated 
Ringers solution is warranted, the use of excessive crystalloid during resuscitation should be avoided. Should the patient's hemodynamics dictate rapid restoration of volume, uncrossed matched blood should be infused until type-specific blood is available. Blood infusions in these patients are typically given as 10 to $20 \mathrm{~mL} / \mathrm{kg}$ boluses. Compared to patients injured by blunt mechanisms, these patients have a higher probability of requiring urgent or immediate, surgical intervention. Snyder and colleagues investigated trends in pediatric GSW at a pediatric Level I trauma center. ${ }^{19}$ The authors found that penetrating injuries were becoming more lethal and patients more likely to require operative exploration than in previous years.

\section{Radiographic Assessment}

If the patient's clinical status allows, and simultaneous with the secondary survey, radiological evaluation should be performed. Patients with penetrating wounds to the neck, chest, abdomen, or pelvis should have a single-view chest radiograph performed. This will help to identify any foreign bodies within the chest cavity, as well as any pathology requiring immediate intervention (eg, hemo- or pneumothorax). In patients with nonfirearm injuries, imaging the involved body region will help to identify the presence of any foreign bodies, debris, fractures, or subcutaneous air. For patients with firearm injuries, plain films are used to determine trajectory based on the location of radio-opaque markers and missiles. Trajectory determination is crucial to define potential anatomic injuries.

\section{CHARACTERISTICS OF FATAL PENETRATING INJURIES}

Numerous investigators have attempted to define potential factors associated with lethal penetrating injuries. These include patient demographics, prehospital vital signs, scene or mechanism characteristics such as intentional or nonintentional, body region injured, and initial resuscitation markers such as lactate and base deficit. ${ }^{20-24}$ While black males were more likely to sustain a lethal penetrating injury from assault, the fatality rate for selfinflicted injuries was highest among white males. ${ }^{20} \mathrm{Ty}-$ burski et al noted that an emergency room systolic blood pressure less than $90 \mathrm{~mm} \mathrm{Hg}$ and initial core temperature less than $34^{\circ} \mathrm{C}$ were the most significant factors predicting mortality in victims of penetrating trauma. ${ }^{21}$ Several authors have demonstrated the prognostic value of base deficit in this patient population, with base deficits of -5 or more predicting mortality rates of at least $25 \% .^{22-24}$ Utilizing the NTDB, Kincaid and colleagues found that admission base deficit reflected not only severity of injury, but predicted mortality as well. ${ }^{24}$ The authors noted that once a child's base deficit was -8 or more the
Table 1. Organs Injured in Children with a Fatal, Nonintracranial Firearm Injury

\begin{tabular}{lc}
\hline \multicolumn{1}{c}{ Organ } & Frequency (\%) \\
\hline Lung & 56.5 \\
Any major vascular & 54.6 \\
Hemopneumothorax & 49.2 \\
Heart & 44.6 \\
Liver & 28.8 \\
Thoracic major vascular & 26.6 \\
Bowel & 26 \\
Abdominal major vascular & 24.9 \\
Diaphragm & 22 \\
Kidney & 11.3 \\
Spleen & 9.6 \\
Esophagus & 9.6 \\
Larynx/trachea & 5.6 \\
Pancreas & 4.5 \\
Spinal cord & 4.0 \\
Tracheobronchial & 2.3 \\
Ureter/bladder & 2.3 \\
\hline
\end{tabular}

Adapted from Nance et al. ${ }^{27}$

mortality rate increased to $25 \%$. With greater base deficits, the fatality risk increased dramatically.

In their evaluation of body region specific fatality rates, Beaman and colleagues noted patients presenting with GSW to the head were more than three times as likely to die (61\% vs. $18 \%$ ) compared to those involving all other body regions. ${ }^{20}$ Patients presenting with a Glasgow Coma Score (GCS) less than 8, unilateral dilated pupil, and transventricular or bihemispheric trajectories were associated with mortality rates of $70 \%$ to $98 \% .^{25} \mathrm{In}$ addition, patients with an infratentorial trajectory had improved outcomes compared with those sustaining a transtentorial injury. ${ }^{26}$

Patients with GSW to the head quite frequently are nonsalvageable. However, those patients with nonintracranial firearm injuries will survive in $75 \%$ to $80 \%$ of cases. Nance et al reviewed the organs injured in patients with nonintracranial but fatal firearm injuries to better understand potentially lethal wounding patterns. ${ }^{27}$ Not surprisingly, the thorax was the body region most commonly injured in those fatally wounded children, but nearly $50 \%$ had injuries to multiple body regions. The most common injuries identified included lung, major vascular and hemopneumothorax (Table 1).

In patients presenting with nonfirearm-related injuries, the ability to predict which wounds are potentially fatal may be more difficult. With regard to air-rifle injuries, those involving the head are more likely to be fatal if the weapon was used in a suicide attempt, at close range, or if the projectile entered the cranium through the orbit or temple. ${ }^{28,29}$ The vast majority of fatal cases involve children, most commonly males, under the age of 16. Intracranial air-rifle injuries have been reported to carry an approximate $30 \%$ mortality. ${ }^{29}$ Those projectiles that pen- 
etrate the chest wall have been associated with fatal injuries from cardiac lacerations. ${ }^{28}$

Fatal stabbings are most likely to be noted in adolescent males with wounds to the anterior mediastinum involving heart and typically result in tamponade in the prehospital setting. ${ }^{29}$ Those wounds sustained as a result of impalement are likely to be fatal in cases where the victim or another bystander has removed the object and thereby released tamponade of a major vascular structure. ${ }^{30,31}$

\section{MANAGEMENT ISSUES BY BODY REGION}

\section{Head Injuries}

\section{Initial Evaluation}

Following the initial trauma survey, neurosurgical consultation, and hemodynamic stabilization, patients with penetrating head injuries should, if possible, undergo immediate computed tomography (CT) evaluation. Plain-film radiographs are unnecessary in facilities with available CT scanners and attempts at obtaining these films cause further delays in definitive evaluation. ${ }^{32} \mathrm{An}$ giography should be utilized in patients with suspected major vascular injury. This should be considered in those patients with facio-orbital entry, associated intracranial hematoma, or transdural trajectory, all of which place the patient at a fourfold or greater risk of aneurysm development. ${ }^{32,33}$ In addition, the use of angiography often provides an additional treatment option in patients with complex skull-based injuries.

\section{Management}

The current approach to surgical management of these wounds is one of early identification and evacuation of "surgical" hematomas, minimal debridement, and aggressive control of intracranial hypertension. ${ }^{34,35}$ The importance of early hematoma evacuation is based on the recognition of improved survival in patients who have earlier surgical intervention. ${ }^{34}$ The purpose of wound debridement in this setting is to prevent infection and minimize the development of posttraumatic seizures due to the presence of devitalized tissue..$^{35}$ The use of craniectomy, although often used in particularly devastating GSWs and in cases of recalcitrant intracranial hypertension, has not been shown to lower infection rates or improve survival. ${ }^{36}$

\section{Prognostic Factors}

Children in general have improved survival rates and functional outcomes as compared to adults with traumatic brain injury (TBI). The mechanism of penetration has a significant influence on the associated mortality and functional recovery. Penetrating brain injuries resulting from tangential missiles or impaled objects have better outcomes than those associated with transcranial GSW ${ }^{37}$ Hypotension is a well-known secondary insult in patients following TBI and, in fact, a single documented episode of hypotension may double the mortality rates in patients with severe brain injury. ${ }^{38} \mathrm{CT}$ scan findings such as bihemispheric lesions and ventricular hemorrhage are associated with higher mortality rates. Other factors associated with poorer outcomes include coagulopathy (especially in patients with lower GCS), fixed and dilated pupils, and persistently elevated intracranial pressure. ${ }^{37}$

\section{Spine Injuries}

As the ISS and mortality associated with GSW continues to increase, so does the incidence of spinal cord injury (SCI). Although SCI from motor vehicle crashes still predominate, GSW have increased and now represent the second most common cause. ${ }^{38,39}$ Both the direct path and the concussive effects of the missile contribute to the destruction of the cord and spine. These patients should undergo extensive evaluation of the spine to determine the trajectory, bony involvement, stability, and possible presence of epidural hematoma. Helical CT of the involved area, with thin cuts $(3 \mathrm{~mm})$ is recommended in patients with penetrating injuries to the spine. In patients with a clinical presentation that does not correlate with radiographic findings, magnetic resonance imaging (MRI) is suggested. In fact, MRI is the most sensitive imaging modality available in the evaluation of the acutely injured spinal cord..$^{40,41}$ MRI is also indicated in those patients with injuries as a result of knife wounds or impalement. ${ }^{42}$

Gunshot wounds to the spine have a potential for instability if the missile fractures pedicles and facets as it traverses the spinal canal. ${ }^{38}$ Patients with incomplete injury and or partial motor function should remain immobilized until stability can be assured. For bullets that have injured the spine, exploration and removal is recommended when the object has a compressive effect or has traversed colon prior to lodging in the spine. ${ }^{43,44}$ Currently, corticosteroids are not indicated in the initial management of SCI resulting from penetrating mechanisms. From a prognostic standpoint, children presenting with incomplete injuries have the greatest likelihood of regaining ambulatory function ( $25 \%$ walking at 1 -year postinjury). ${ }^{43}$

\section{Neck Injuries}

\section{Initial Management and Diagnosis}

Nearly $25 \%$ of patients with penetrating neck injuries will require urgent intubation. The intubation itself can be complicated by the associated expanding neck hematoma and laryngotracheal injury. Early intubation and airway control are of paramount importance. The most 
experienced person available should be designated for control of the airway. A brief neurological exam prior to sedation or chemical paralysis in these patients is mandated.

Physical findings such as an expanding neck hematoma, active or pulsatile bleeding, bruit, lateralizing neurologic signs, stridor, or obvious laryngotracheal injury are considered "hard" signs and require immediate operative intervention. Active bleeding, if encountered, should be initially controlled with digital pressure. This should be continued until proximal and distal control is operatively obtained. Wounds should not be probed, cannulated, or locally explored. These maneuvers can dislodge clot and lead to uncontrolled hemorrhage or embolism..$^{45}$ If the patient's status allows, a chest radiograph should be obtained to look for any associated life-threatening issue (eg, tension pneumothorax) that requires treatment prior to surgery.

Those without "hard" signs are managed with appropriate trajectory guided diagnostic studies. "Soft" signs include hoarseness, hematemesis, hemoptysis, or a change in voice, dysphagia, or odynophagia. In the absence of "hard" or "soft" signs of vascular injury, several authors have concluded that penetrating injuries limited to Zone II can be safely managed on physical exam alone. ${ }^{46-48}$ Biffl et al concluded that asymptomatic patients with Zone II neck injuries could be observed with less than a $1 \%$ chance of a missed injury. ${ }^{48}$ Zone I and III injuries have traditionally been investigated with angiography. This remains the gold standard, because of operative exposure difficulties. In addition to the evaluation and exclusion of injury, angiography aids in planning the operative approach when more than one zone is involved. ${ }^{45}$

Dramatic improvements in image quality and advances in software have made helical CT angiography (CTA) an alternative to conventional angiography. Munera and colleagues noted CTA to be a safe alternative to conventional angiography in patients with penetrating neck injuries and could be used as the initial method of evaluation, reserving conventional angiography for those patients with equivocal studies. ${ }^{49}$ This has particular benefit for children in whom angiography is often difficult with significant morbidity. Helical CT is also useful in determining missile trajectory. Several institutions have examined the utility of CT scan in accurately determining the missile trajectory and, therefore, defining the anatomic injuries in penetrating neck trauma. The sensitivity of CT scan for identifying significant injury was $100 \%$ with a specificity over $90 \% .^{50}$ It was concluded that CT scan could help eliminate the need for mandatory exploration and limit the need for further diagnostic testing.
Clinical findings suggestive of hypopharyngeal or esophageal penetration include dysphagia, odynophagia, hemoptysis, and subcutaneous emphysema. ${ }^{45}$ Diagnostic options range from mandatory surgical exploration to various combinations of radiographic and endoscopic inspection to close clinical observation. Physical examination, however, does not appear reliable in excluding injuries to the esophagus following GSW. ${ }^{46,51}$ Srinivasan et al investigated the use of flexible endoscopy in the evaluation of penetrating neck injuries and noted a sensitivity of $100 \%$ and specificity of $92 \%$ for detecting esophageal injuries. ${ }^{52} \mathrm{~A}$ negative endoscopic evaluation can be followed by a contrast esophagogram to further minimize the risk of missed injury. Physical examination combined with both endoscopy and esophagography will detect $100 \%$ of penetrating esophageal injuries. .3-55 $^{5}$

The risk of death and complications associated with laryngeal and tracheal injuries can be minimized by aggressive airway control and an expedient search for occult injuries. Patients with laryngotracheal injury often present with obvious signs of airway injury, such as stridor, dyspnea, or subcutaneous crepitance. As with the digestive tract, physical examination findings are sensitive for detecting airway injury but lack specificity. Diagnostic laryngoscopy is utilized to evaluate the hypopharynx following Zone III injuries, whereas tracheobronchoscopy is better suited for examination of Zones I and II. The sensitivity of these modalities alone is approximately $90 \%$, but increases to $100 \%$ when combined. ${ }^{45}$

\section{Operative Approaches}

In injuries involving Zone I, a median sternotomy with a sternocleidomastoid incision (SCM) is usually the most useful approach. This is especially important when time does not permit adequate preoperative investigation. In the unstable patient, injuries to the proximal one third of the left subclavian are best controlled through an anterolateral thoracotomy through the third intercostal space. A supraclavicular counter-incision is then made to achieve distal control. To achieve adequate exposure to injuries involving the innominate or common carotid arteries, a median sternotomy provides ample exposure and the ability to achieve proximal (and often distal) control. Utilization of a supraclavicular incision can provide exposure and allow for vascular control of injuries to the right subclavian and distal two thirds of the left subclavian artery. If one is required to obtain vascular control of a vertebral artery injury, a supraclavicular incision provides optimal exposure; if the area of injury is not known preoperatively, the SCM remains the most versatile incision. ${ }^{56}$ Exposure is maximized by ligation of the thyrocervical trunk and division of the anterior scalene. 
Care should be taken to avoid and protect the phrenic nerve.

Although an anterior SCM incision will provide adequate exposure of unilateral neck injuries in Zone II, transcervical or bilateral wounds are better exposed with a transverse (collar) incision. Both of these incisions can be quickly extended into the chest should a sternotomy be required. ${ }^{57}$ If the extent of injury extends into either Zone I or Zone III or the point necessary for vascular control lies outside of this area, several maneuvers may be employed. As with Zone I injuries, a sternotomy may be used if more proximal exposure is necessary. For those extending distally (or into Zone III), division of the omohyoids and or digastrics will increase exposure. If necessary, anterior subluxation of the mandible may be utilized for those injuries requiring extreme distal exposure. ${ }^{58}$

Due to the inherent difficulty in evaluating and obtaining vascular control in this area, selective management of injuries to Zone III has arisen. In addition to subluxation of the mandible, resection of the angle of the mandible or styloid process may also be undertaken. ${ }^{45}$ If proximal control can be obtained, distal control of Zone III (and even some Zone II) injuries may be obtained through the placement and inflation of a Fogarty catheter. This allows the surgeon to further expose necessary vessels for vascular control or provides control of distal bleeding until interventional radiology or endovascular treatments can be employed.

\section{Management Principles}

Vascular injuries, especially those involving the carotid artery, account for almost one third of life-threatening injuries in patients with penetrating neck trauma. Carotid injuries should be repaired unless the surgeon is faced with uncontrollable hemorrhage or a devastating vessel injury that cannot be temporized with a vascular shunt. ${ }^{45}$ A temporary vascular shunt should be utilized if distal pressures are less than 50 to $60 \mathrm{~mm} \mathrm{Hg} .{ }^{57}$ Primary repair should be attempted on all common and internal carotid injuries following debridement of nonviable tissues. Unless the injury is at or near the bifurcation, those involving the external carotid should be ligated. Defects greater than $2 \mathrm{~cm}$ should be repaired using saphenous vein. The internal jugular vessels should not be utilized for conduit in this setting considering the disruption to venous outflow associated with their harvest. ${ }^{56}$ Repair of the innominate and subclavian arteries can be accomplished using similar principles as those applied to the carotid arteries. If the diagnosis of a vertebral artery injury is made in a hemodynamically stable patient without active external hemorrhage, the vessel should be embolized. Should the patient present with active hemorrhage or experienced personnel are not available for angiography and embolization, an attempt at operative control is indicated. After ligation of the proximal artery, a Fogarty catheter can be passed in an antegrade fashion and be left in place to occlude the distal injury. Interventional or endovascular assistance should then be expeditiously obtained. ${ }^{45,56}$

The repair of an injury to the cervical esophagus is best approached through an anterior SCM incision, unless associated with a laryngotracheal injury. In these combination injuries a collar incision offers better exposure. Maximal exposure of the esophagus is achieved through retraction of the trachea and thyroid medially and the carotid sheath laterally. ${ }^{59}$ Nonviable edges should be sharply debrided prior to primary repair, which is performed with an interrupted submucosal (absorbable suture) and a muscular layer (nonabsorbable suture). The patient should remain NPO until a contrast swallow has excluded a leak.

Most laryngeal defects from penetrating trauma can be repaired primarily. Although proper debridement should proceed any attempt at primary repair, all viable tissues should be spared.57,60,61 Early fracture stabilization (Kirschner wires) of involved components and repair of mucosal lacerations has been associated with improved airway and voice quality. ${ }^{61}$ If the cartilaginous framework has been disrupted beyond management with a primary repair, some authors advocate "stenting" the airway with the indwelling endotracheal tube or with the placement of a silicone stent.$^{60,61}$ Tracheostomy should be avoided in the area of injury, but if necessary should be placed distal to the repair to "protect" the anastomosis. Tracheal injuries are repaired primarily in a singlelayer fashion, using an absorbable (3-0) suture. As with laryngeal injuries, viable tissue should be conserved and search for recurrent laryngeal nerves avoided. ${ }^{60}$ Large defects $(>3 \mathrm{~cm})$ can be repaired primarily after adequate mobilization; best accomplished by releasing anterior (thyroid and suprahyoid) attachments, staying clear of the lateral blood supply. Vascularized flaps should be employed to buttress the repair, decreasing the risk of fistula formation. With very large defects $(>6 \mathrm{~cm}$, those requiring vascularized flaps) a tracheostomy should be placed at the time of the initial operation. Avoidance of flexion in the postoperative period ( 5 to 7 days) can be achieved with cervical collar immobilization. ${ }^{61}$

\section{Thoracic Injuries}

\section{Initial Presentations}

The past decade has been witness to a dramatic increase in the incidence of penetrating thoracic injuries and fatalities in children. ${ }^{62-66}$ While thoracic injuries are responsible for only $15 \%$ of blunt traumatic deaths, $97 \%$ of pediatric deaths from penetrating chest trauma are the 
direct result of thoracic injury ${ }^{67}$ Nance and colleagues noted that thoracic GSW are more destructive in patients less than 12 years of age. ${ }^{27}$ They also noted these patients were more likely to present with unstable vital signs and an increased need for thoracotomy. In a review of all fatal, nonintracranial firearm injuries in children, thoracic injuries were noted in almost $80 \% .{ }^{27}$ In addition, over $95 \%$ of these children died in the first $24 \mathrm{~h}$. Similarly, Acosta et al found thoracic vascular injuries were the most common cause of death in the first hour after admission. These findings suggest that uncontrolled hemorrhage from the injury, rather than delayed complications, were the primary cause of death. Therefore, if attempts at salvage of these patients are to be successful, adherence to ATLS guidelines and aggressive, sometimes innovative, surgical interventions are mandatory. ${ }^{27}$

\section{Initial Diagnostic Modalities}

Chest radiographs should be obtained following the primary survey in victims of penetrating chest injuries. These and other radiographs of affected regions will allow the determination of trajectory to assist the physician in identifying possible anatomic injuries. As with transabdominal and transcervical GSW, the trajectory and likely injury patterns in thoracic injuries can be defined using helical CT. Stassen et al concluded that contrast enhanced helical CT scan of the chest was a safe, practical, and cost- effective tool in the exclusion of major injuries associated with transmediastinal GSW. ${ }^{68}$ They concluded that patients with low-risk trajectories could be safely observed without further diagnostic evaluation. In light of the fact that few patients will present with a single wound (except in cases of impalement or stabbing), focused assessment for the sonographic evaluation of trauma (FAST) provides a noninvasive means of establishing priorities in children with multiple torso wounds. ${ }^{69}$ FAST provides a means of evaluating the patient for evidence of pericardial fluid, hemothorax, or hemodynamically significant intraperitoneal fluid.

\section{Early Management Principles}

The most common injuries involving the chest are hemothorax and pneumothorax (Table 2) ${ }^{62}$ After airway control, attention should be directed at evacuation of hemo- or pneumothorax with needle decompression and/or thoracostomy tube placement (ATLS). Thoracotomy is indicated in patients with immediate chest tube output of $20 \%$ of the patient's blood volume or persistent output of 2 or more $\mathrm{mL} / \mathrm{kg}$ per hour. The appropriate indications for emergency room thoracotomy (ERT) are still of some debate. In the child with a penetrating injury, ERT may be indicated in the child with loss of documented vital signs (in the ER or en route) but is of limited value in the patient with no documented signs of
Table 2. Frequency of Intrathoracic Organs Injured

\begin{tabular}{cc}
\hline Organ & Frequency (\%) \\
\hline Pneumo/hemothorax & 64 \\
Pneumothorax & 23 \\
Pneumohemothorax & 24 \\
Hemothorax & 18 \\
Lung & 29 \\
Contusion & 14 \\
Laceration & 10 \\
Diaphragm & 15 \\
Heart & 13 \\
Major vessel & 10 \\
Esophagus & 1 \\
\hline
\end{tabular}

Adapted from Cooper et al. ${ }^{67}$

life. ERT may be useful in cases of suspected cardiac tamponade from penetrating chest trauma. ${ }^{70-73}$ Institutions that have employed more stringent definitions of patients in whom ERT should be employed have seen dramatic improvements (from $<5 \%$ to almost $50 \%$ ) in their survival rates. ${ }^{73}$ Should a tamponade be encountered, the pericardium should be opened in a vertical fashion above and along the phrenic nerve course, evacuating the hematoma or clot. Lacerations to the heart and great vessels can be quickly repaired using a 3-0 or 4-0 polypropylene suture. In more complicated cases, damage control techniques (such as temporary closure of cardiac defects or cardiopulmonary bypass) can be employed. ${ }^{68}$ In cases of pulmonary parenchymal damage, tractotomies can expedite exposure, providing a rapid and effective alternative to lobectomy in patients with severe lung injuries. Gasparri and colleagues noted that this approach offered rapid exposure of bleeding vessels, less likelihood of parenchymal hematomas, and shorter operative times. $^{74}$

\section{Abdominal Injuries}

\section{Initial Evaluation and Diagnosis}

As the majority of penetrating injuries to the abdomen will require surgical intervention, preparation of an operating room for laparotomy should occur simultaneously with the primary survey. During the secondary survey, the abdomen is evaluated for any physical findings that may suggest possible intraabdominal injury. Distention may develop from hemorrhage or hollow visceral injury with free air. Percussion of the abdomen may help distinguish the dullness of fluid from the tympany of free air. Tenderness may be present as a result of diffuse peritoneal inflammation from blood or enteric contents, or locally as a result of soft tissue destruction.

Chest and abdominal radiographs are usually indicated to help determine bullet trajectory and search for possible retained missiles, fragments or bony injury. A decubitus or upright view may demonstrate free air in the 
Table 3. Frequency of Intraabdominal Organs Injury

\begin{tabular}{lc}
\hline Organ & Frequency (\%) \\
\hline Gastrointestinal tract & 70 \\
Stomach & 13 \\
Duodenum & 4 \\
Jejunum/ileum & 24 \\
Colon/rectum & 27 \\
Liver & 27 \\
Major vessel & 19 \\
Kidney & 10 \\
Spleen & 9 \\
Genitourinary tract & 8 \\
Pancreas & 6 \\
\hline
\end{tabular}

abdomen, which further supports the need for operative intervention. CT scan has been advocated for evaluating tangential abdominal wounds or wounds in the hepatic region that may not require celiotomy. ${ }^{75,76}$ If an extraperitoneal trajectory is determined, laparotomy may be avoided. In addition, the adult literature indicates that injuries that clearly involve the liver, in the absence of other indications for surgical intervention, may be managed expectantly. There is some conflicting data in children, however, and the question requires further investigation. ${ }^{77} \mathrm{CT}$ scan may also be of benefit in evaluation of transpelvic and gluteal GSW; CT scans obtained to evaluate GSW in this region should include IV, oral and rectal contrast. ${ }^{78}$ While the utility of FAST for blunt injury in the pediatric patient is not clear, it may be quite useful when it is used to help the physician determine which body cavity (pericardial, pleural, or peritoneal) may contain fluid in the patient with multiple GSWs.

Diagnostic peritoneal lavage (DPL) has been advocated as a tool to determine the need for laparotomy in penetrating trauma, while others have found this technique less reliable and nonspecific. The decision to perform a DPL should be that of the operating surgeon as the interpretation of the results will determine the need for laparotomy. Laparoscopy may also be useful to help determine if peritoneal violation has occurred. If peritoneal penetration is identified, the patient should undergo a formal laparotomy for thorough exploration. The laparoscope may also be valuable in assessing the diaphragms in those cases in which the trajectory suggests a possible thoracoabdominal path.

In selected patients, nonoperative management of stab wounds or GSW may be indicated. This decision must be individualized and the patient examined on frequent intervals to detect peritoneal signs. ${ }^{76,78}$ Deterioration of the physical exam or vital signs mandates urgent laparotomy.

Potential intraabdominal injuries from a gunshot wound can be varied thus one must assume and prepare for the worst (Table 3). The chest, abdomen, and groin should be prepped and draped into the operative field.
The left arm is extended above the head to provide access to the chest in case thoracotomy is necessary. Maintaining the patient's core body temperature is a priority during the laparotomy. The operating room should be warmed and all fluids and blood products (if necessary) run through a warming device. Broad-spectrum antibiotics (eg, second-generation cephalosporins) are administered preoperatively. After entering the abdomen, all four quadrants should be packed with laparotomy sponges to control hemorrhage. Each quadrant is then inspected for ongoing hemorrhage and repacked if necessary. Control of hemorrhage is of primary importance. After control of hemorrhage, attention turns to identification of injuries and control of contamination. The bowel should be inspected meticulously from diaphragm to rectum. In general, an even number of enterotomies should be identified as bowel injuries are typically through and through. Retroperitoneal hematomas should be explored to identify potential major vascular injuries.

The management of hollow organ injuries is based on the extent of injury. Focal injuries with minimal blast effect can be managed with debridement and primary repair if adequate caliber can be assured. Extensive injury or tissue devitalization usually requires resection and reconstruction. Multiple injuries in close proximity (as often occur in the small bowel) are best managed by limited bowel resection incorporating all holes with a primary anastomosis rather than repair of individual wounds. The management of colonic injuries remains controversial. Most adult studies suggest primary repair or resection with repair is appropriate for the majority of colonic injuries. Colostomy is reserved for complex injuries or the unstable patient. Such an approach is likely safe in children but is as yet unproven.

Solid organ injuries such as those involving the liver or spleen are typically amenable to packing or local maneuvers. In the minority of cases, resection may be required for hemostasis. Attempts at splenic salvage are warranted in the stable pediatric patient to avoid the potential for overwhelming post splenectomy sepsis.

Abdominal vascular injuries, although somewhat uncommon, are associated with a high mortality. Hemodynamic instability in the setting of an abdominal gunshot wound is likely the result of a vascular injury. Consideration should be given to thoracotomy and cross-clamping of the aorta prior to entering the abdomen as decompression of abdominal tamponade effect may prove rapidly fatal. Additional maneuvers to control exsanguinating hemorrhage include cross-clamping of the aorta at the suprahepatic level or compression of the aorta with an instrument. Once the vascular injury is identified, local control should be established and aortic occlusion released. Management of the injured vessel should be individualized. Most injuries are amenable to debride- 
ment with primary repair or in selected cases, ligation. If vascular reconstruction is necessary, native internal jugular vein or hypogastric artery is a potential conduit. Impalements represent a truly unique subset of penetrating injuries. Their often spectacular presentation can lead to great distraction and loss of management focus. These injuries are best managed in the operating room where complete assessment of injuries can be performed and an appropriate treatment strategy developed. The management is highly individualized based on the nature and trajectory of the impaling instrument. Fistulotomy-like incisions that extend from the entrance to exit wound provide adequate exposure to establish proximal and distal vascular control prior to removal of the implement. Management of these injuries is frequently a team effort involving surgery, neurosurgery, and orthopedic surgery.

\section{Extremity Injuries}

The treatment of fractures associated with GSWs in children is never easy, particularly if the wounds are caused by high-velocity firearms or shotguns. Bony defects, the presence of peripheral nerve damage, and involvement of the joint negatively affect the outcome, increasing complications and the need for additional procedures. ${ }^{79,80}$ Internal bone transport is an effective method in the treatment of bone and soft-tissue defects associated with GSWs in children. Patients with penetrating extremity injuries should be evaluated with physical examination and pulse pressure indices (systolic pressure unaffected limb/systolic pressure in affected limb) to reliably exclude vascular injuries in the involved limb. Those children with a normal exam and anklebrachial (AB) indices of 0.9 or greater may be safely discharged. In symptomatic patients and those with $\mathrm{AB}$ indices less than 0.9 usually require angiographic evaluation. ${ }^{79}$ The younger age of the patients contributes to their limb salvage rates being higher than predicted. Additionally, expeditious surgical exploration and early, but judicious use of arteriograms is associated with improved outcomes. ${ }^{80}$

\section{DAMAGE CONTROL}

The damage control concept centers on the early identification of life-threatening injuries and the decision to avoid complicated, sometimes lengthy, definitive repairs. ${ }^{45}$ Recently, damage control techniques have been applied to the pediatric trauma population. ${ }^{81}$ In cases of abdominal injury, the initial laparotomy is abbreviated and involves expeditious tamponade of active bleeding with packing and control of contamination by closure of enterotomies. No attempts are made to definitively manage injuries that can safely be delayed until the patient is more stable. A temporary abdominal closure of skin only is performed to prevent intraabdominal hypertension. In the second phase, aggressive resuscitation continues in the intensive care unit with a focus on rewarming and correction of acidosis, and coagulopathy. The resuscitation phase typically lasts 12 to $24 \mathrm{~h}$. The third phase involving definitive management of injuries and fascial closure should be undertaken when adequate resuscitation has been achieved. In addition to its use in abdominal injuries, the application of damage control principles can be applied to neck, chest, and extremity injuries..$^{82,83}$ The damage control approach, although resource intensive, may salvage patients with an otherwise high mortality.

\section{REFERENCES}

1. http://www.cdc.gov/ncipc/factsheets/childh.htm

2. http://www.facs.org/dept/trauma/ntdbannualreport2003.pdf

3. Nance ML, Stafford PW, Schwab CW: Firearm injuries among urban youth during the last decade: An escalation in violence. J Pediatr Surg 52:949-952, 1997

4. Holland AJ, Kirby R, Browne GT, et al: Penetrating injuries in children: Is there a message? J Paediatr Child Health 38:487-491, 2002

5. Beaver BL, Moore VL, Peclat M, et al: Characteristics of pediatric firearm fatalities. J Pediatr Surg 25:97-100, 1990

6. Christoffel KK: Toward reducing pediatric injuries from firearms: Charting legislative and regulatory course. Pediatrics 88:294-305, 1991

7. Fingerhut LA, Christoffel KK: Firearm related death and injury among children and adolescents. Future Child 12(2):25, 2002

8. McNeill AN, Annest JL: The ongoing hazard of BB and pellet gun related injures in the United States. Ann Emerg Med 26:187-194, 1995

9. Arria AM, Wood NP, Anthony JC: Prevalence of carrying a weapon and related behavior in urban school children 1989-1993. Arch Pediatr Adol Med 149:1345-1350, 1995

10. Du Rant RH, Krowchuk DP, Kreiter S, et al: Weapon carrying on school property among middle school students. Arch Pediatr Adol Med 153:21-26, 1999
11. Crandall C, Olson L, Fullerton L, et al: Guns and knives in New Mexico: Patterns of penetrating trauma, 1978-1993. Acad Emerg Med 4:263-267, 1997

12. Duff A: Impalement without serious injury. Br J Surg 54:240241,1967

13. Kelly IP, Attwood SA, Quilan W, et al: The management of impalement injury. Injury 26:191-193, 1995

14. Asch MJ, Lippmann M, Nelson RJ, et al: Truck aerial impalement injury of the thorax in an 8 year-old boy. J Pediatr Surg 9:251-252, 1974

15. American College of Surgeons Advanced Trauma Life Support (ATLS) manual. Chicago, ACS, 1997

16. Martin RR, Bickell WH, Pepe PE: Prospective evaluation of pre-operative fluid resuscitation in hypotensive patients with truncal injury: a preliminary report. J Trauma 33:354, 1992

17. Deakin CD: Early fluid resuscitation in hemorrhagic shock. Eur J Emerg Med 1:83, 1994

18. Bickell WH, Wall MJ Jr, Pepe PE, et al: Immediate versus delayed fluid resuscitation for hypotensive patients with torso injuries. N Engl J Med 331:1105-1109, 1994

19. Snyder AK, Chen LE, Foglia RP, et al: An analysis of pediatric gunshot wounds treated at a level I pediatric trauma center. J Trauma 54:1102-1106, 2003 
20. Beaman V, Annest JL, Mercy JA, et al: Lethality of firearm related injuries in the United States population. Ann Emerg Med $35: 258-266,2003$

21. Tyburski JG, Wilson RF, Dente C, et al: Factors affecting mortality rates in patients with abdominal vascular injury. J Trauma 50:1020-1026, 2001

22. Eachempati SR, Robb T, Ivatury RR, et al: Factors associated with mortality in patients with penetrating abdominal vascular trauma. J Surg Research 108:222-226, 2002

23. Randolph LC, Takacs M, Davis KA: Resuscitation in the pediatric trauma population: admission base deficit remains an important prognostic indicator. J Trauma 53:838-842, 2002

24. Kincaid EH, Chang MC, Letton RW, et al: Admission base deficit in pediatric trauma: A study using the NTDB. J Trauma 51:332335,2002

25. Martin RS, Siqueria MG, Santos MT, et al: Prognostic factors and treatment of gunshot wounds to the head. Surg Neurol 60:98-104, 2003

26. Nathoo N, Chite SH, Edwards PJ, et al: Civilian infra-tentorial gunshot injuries: Outcome analysis of 26 patients. Surg Neurol 58:225233,2002

27. Nance ML, Branas CC, Stafford PW, et al: Nonintracranial fatal firearm injuries in children: Implications for treatment. J Trauma 55: 631-635, 2003

28. Milroy CM, Clark JC, Carter N, et al: Air weapon fatalities. J Clin Pathol 51:525-529, 1998

29. Bratton SL, Dowd MD, Brogan TV, et al: Serious and fatal air gun injuries: More than meets the eye. Pediatrics 100:609-612, 1997

30. Karger B, Teige K, Bajanowski T, et al: Bizarre impalement fatalities-where is the implement? J Forensic Sci 47:389-391, 2002

31. Prahlow JA, Ross KF, Lene WJ, et al: Accidental sharp force injury fatalities. Am J Forensic Med Pathol 22:358-366, 2001

32. Anonymous: Neuroimaging in the management of penetrating brain injury. J Trauma 51:S7-11, 2001 (suppl 2)

33. Aarabi B: Management of traumatic aneurysms caused by highvelocity missile head wounds. Neurosurg Clin N Am 6:775-797, 1995

34. Helling TS, McNabney WK, Whittaker CK, et al: The role of early surgical intervention in civilian gunshot wounds to the head. J Trauma 32:398-400, 1992

35. Anonymous: Surgical management of penetrating brain injury. J Trauma 51:S16-25, 2001 (suppl 2)

36. Rish BL, Dillon JD, Caveness WF, et al: Evolution of craniotomy as a debridement technique for penetrating craniocerebral injuries. J Neurosurg 53:772-775, 1980

37. Anonymous: Prognosis of penetrating brain injury. J Trauma 51suppl 2:S44-85, 2001

38. Levi L, Borovich B, Guilburd JW: Wartime neurosurgical experience in Lebanon, 1982-1985: Penetrating craniocerebral injuries. Br J Med Sci 26:548-554, 1990

39. Waters RL, Sie IH: Spinal cord injury from gunshot wounds to spine. Clin Orthop Relat Res 408:120-125, 2003

40. Flanders AE, Schaefer DM, Doan HT, et al: Acute cervical spine trauma: Correlation of MRI findings with degree of neurological deficit. Radiology 177:25-33, 1990

41. Uppot RN, Ghey VK, Gould SW, et al: Pneumocephalus and Brown-Sequard's neurologic injury caused by stab wound to the neck. AJR Am J Roentgenol 173:1504, 1992

42. Alkan A, Baysal T, Sarac K, et al: Early MRI findings in stab wounds of the cervical spine: Two case reports. Neuroradiology 44 : 64-66, 2002

43. Yoshida GM, Garland D, Waters RL: Gunshot wounds to the spine. Orthop Clin N Am 20:109-116, 1995
44. Aarabi B, Alibaii E, Taghipur M, et al: Comparative study of functional recovery for surgically explored and conservatively managed spinal cord missile injuries. Neurosurgery 39:1133-1140, 1996

45. Cotton BA, Pryor JP: Penetrating injuries to the neck, in Mahoney PF, Ryan J, Brooks AJ, Schwab CW (eds): Ballistic Trauma-A Practical Guide (2nd ed). London, Springer-Verlag, 2004 (in press)

46. Demetriades D, Theodorou D, Cornwell EE III, et al: Transcervical gunshot injuries: Mandatory operation is not necessary. J Trauma 40:758-760, 1996

47. Klyachkin ML, Rohmiller M, Charash WE: Penetrating injuries of the neck: Selective management evolving. Am Surg 63:189-194, 1997

48. Biffl WL, Moore EE, Rehse DH, et al: Selective management of penetrating neck trauma based on cervical level of injury. Am J Surg 174:678-682, 1997

49. Munera F, Soto JA, Palacio D, et al: Diagnosis of arterial injuries caused by penetrating trauma to the neck: Comparison of helical CT angiography and conventional angiography. Radiology 216: 356-362, 2002

50. Mazolewski PJ, Curry JD, Browder T, et al: CT scan can be used for surgical decision making in Zone II penetrating neck injuries. J Trauma 51:315-319, 2001

51. Demetriades D, Theodorou D, Cornwell EE III, et al: Penetrating injuries of the neck in patients in stable condition: Physical examination, angiography, or color-flow Doppler. Arch Surg 130:971-975, 1995

52. Srinivasan R, Haywood T, Horowitz B, et al: Role of flexible endoscopy in the evaluation of possible esophageal trauma after penetrating injuries. Am J Gastroenterol 95:1725-1729, 2002

53. Demetriades D, Theodorou D, Cornwell EE III, et al: Evaluation of penetrating injury of the neck: Prospective study of 223 patients. World J Surg 21:41-48, 1997

54. Weigelt JA, Thal ER, Snyder WH III, et al: Diagnosis of penetrating cervical esophageal injuries. Am J Surg 154:619-622, 1987

55. Glatterer MS Jr, Toon RS, Ellestad C, et al: Management of blunt and penetrating external esophageal trauma. J Trauma 25:784792,1985

56. Wisner DH: Cervical vascular injury, in Trunkey DD, Lewis FR (eds): Current Therapy of Trauma. St. Louis, MO, Mosby, 1999, pp 109-196

57. Britt LD, Peyser MB: Penetrating and blunt neck trauma, in Mattox KL, Feliciano DV, Moore EE (eds): Trauma. New York, New York, McGraw-Hill, 2000, pp 437-448

58. Lickweg WG, Greenfield LJ: Management of penetrating carotid arterial injury. Ann Surg 188:582, 1978

59. Demetriades D, Velmahos G, Asensio JA: Cervical pharyngoesophageal and laryngotracheal injuries. World J Surg 25:1044-1048, 2001

60. Bee TK, Fabian TC: Penetrating neck trauma, in Cameron J (ed): Current Surgical Therapy. St. Louis, MO, Mosby, 2001, pp 1170-1174

61. Mathison DJ, Grillo H: Laryngotracheal trauma. Ann Thor Surg 43:254, 1987

62. Nance ML, Sing RF, Reilly PM, Templeton JM, Schwab CW: Thoracic gunshot wounds in children under 17 years of age. J Pediatr Surg 31:931-935, 1996

63. Beaver BL, Moore VL, Peclet M, Haller JA, Smialek JJ, Hill JL: Characteristics of pediatric firearm fatalities. J Pediatr Surg 25:97-100, 1990

64. Madiba TE, Thomson SR, Mdlalose N: Penetrating chest injuries in the firearm era. Injury 32:13-16, 2001

65. Hall JR, Reyes HM, Meller JL, Loeff DS, Dembek RG: The new epidemic in children: penetrating injuries. J Trauma 39:487-491, 1995 
66. Eren S, Balci AE, Ulku R, et al: Thoracic firearm injuries in children: Management and analysis of prognostic factors. Eur J Cardiothorac Surg 23:888-893, 2003

67. Cooper A, Barlow B, DiScala C, et al: Mortality and truncal injury: The pediatric perspective. J Pediatr Surg 29:33-38, 1994

68. Stassen NA, Lukan JK, Spain DA, et al: Re-evaluation of diagnostic procedures for transmediastinal gunshot wounds. J Trauma 53:635-638, 2002

69. Asensio JA, Arroyo H Jr, Veloz W: Penetrating thoraco-abdominal injuries: ongoing dilemma-Which cavity and when? World J Surg 26:539-543, 2002

70. Blake DP, Gisbert VL, Ney AL, et al: Survival after emergency department versus operating room thoracotomy for penetrating cardiac injuries. Am Surg 58:329-333, 1992

71. Velmahos GC, Degiannis E, Souter I, et al: Outcome of a strict policy on emergency department thoracotomies. Arch Surg 130:774777,1995

72. Lewis G, Knottenbelt JD: Should emergency room thoracotomy be reserved for cases of cardiac tamponade? Injury 22:5-6, 1991

73. Aihara R, Millham FH, Blansfield J, et al: Emergency room thoracotomy for penetrating chest injury: Effect of an institutional protocol. J Trauma 50:1027-1030, 2001

74. Gasparri M, Karmy-Jones R, Kralovich KA, et al: Pulmonary tractotomy versus lung resection: Viable options in penetrating lung injury. J Trauma 51:1092-1097, 2001
75. Grossman MD, May AK, Schwab CW, et al: Determining anatomic injury with $\mathrm{CT}$ in selected torso gunshot wounds. J Trauma 45:446-456, 1998

76. Ginzburg E, Carrillo EH, Kopleman T, et al: The role of CT in selective management of gunshot wounds to the abdomen and flank. J Trauma 45:1005-1009, 1998

77. Dicker RA, Sartorelli KH, McBride WJ, et al: Penetrating hepatic trauma in children: Operating room or not? J Pediatr Surg 31: 1189-1191, 1996

78. Chiu WC, Shanmuganathan K, Mirvis SE, et al: Determining the need for laparotomy in penetrating torso trauma: A prospective study using triple contrast enhanced abdominal pelvic CT. J Trauma 51:860869,2001

79. Stucky W, Loder RT: Extremity gunshot wounds in children. J Pediatr Orthop 11:64-71, 1991

80. Washington ER, Wayne AL, William AJR: Gunshot wounds to the extremities in children and adolescents. Orthop Clin N Am 26:1928,1995

81. Stylianos S: Abdominal packing for severe hemorrhage. J Pediatr Surg 33:339-342, 1998

82. Vargo DJ, Battistella FD: Abbreviated thoracotomy and temporary chest closure. Arch Surg 136:21-24, 2001

83. Firoozmand E, Velmahos GC: Extending damage control principles to the neck. J Trauma 48:541-543, 2000 